http://jmscr.igmpublication.org/home/ ISSN (e)-2347-176x ISSN (p) 2455-0450 crossref DOI: https://dx.doi.org/10.18535/jmscr/v9i5.14

\title{
Pentazocine induced ulceration masquerading medium vessel vasculitis
}

\author{
Authors \\ Dr Ritu Rani ${ }^{1}$, Dr Reena K Sharma ${ }^{2}$, Dr Mudita Gupta ${ }^{3 *}$ \\ ${ }^{1}$ Dermatologist, Civil Hospital Kangra, H.P. \\ ${ }^{2}$ Dermatologist, Civil Hospital Kangra \\ ${ }^{3}$ Assistant Professor, Department of Dermatology, IGMC, Shimla \\ *Corresponding Author \\ Dr Mudita Gupta \\ Assistant Professor, Department of Dermatology, IGMC, Shimla, India
}

\begin{abstract}
We herein describe a case of 45-year-old female, who presented with multiple non-healing ulcers over both shins from past 2 years. She was being treated for vasculitis from some private institution till date. After proper history given by the attendant she was found to be using pentazocine injections for multiple somatic complaints. With subsequent psychiatric counseling, the lesions healed after 3 months of treatment.

Keywords: pentazocine, somatic symptoms, cutaneous ulceration.
\end{abstract}

\section{Introduction}

Pentazocine is a low cost effective analgesic and its prolonged use can lead to psychological and physical dependence. Various cutaneous side effects have been reported in $1971 .{ }^{[1]}$ History of abuse is difficult to seek. The most prominent side effect of pentazocine use / abuse is cutaneous ulcerations. We report a case who presented with multiple leg ulcers due to drug abuse.

\section{Case Report}

A 44 year old female presented with multiple leg ulcers from last 2 years. On clinical examination there were multiple well defined, punched out ulcers of size around $2 \times 2 \mathrm{~cm}$ with perceptible violaceous hue of the margin [Fig $1 \mathrm{a} \& 1 \mathrm{~b}]$. The surrounding skin was hyperpigmented and indurated. No venous access was found and all veins were thickened and fibrosed [Fig 2a]. There were multiple atrophic scars on all limbs [Fig2b]. Routine laboratory investigations including complete blood counts, liver and renal function tests, urine examination, chest X-ray, color doppler ultrasound were all within normal limits. Serology for vasculitis (ANA, ANCA and anti dsDNA) and infections (HBV, HCV and HIV) was negative. A skin biopsy specimen showed changes of vasculitis with predominant neutrophilic infiltrate. Connective tissue diseases, vasculitis and dermatitis artefacta were ruled out. Based on these findings, we suspected intravenous drug abuse however she denied such history in the past. She had history of multiple somatic complaints for which she used to take pentazocine and phenargan injections from last 8 years from a local quack. Self administration of injections was 


\section{JMSCR Vol||09||Issue||05||Page 76-78||May}

also done by the patient frequently as told by the attendant. With the help of aseptic dressings and psychiatric counseling the lesions healed after 3 months of treatment.

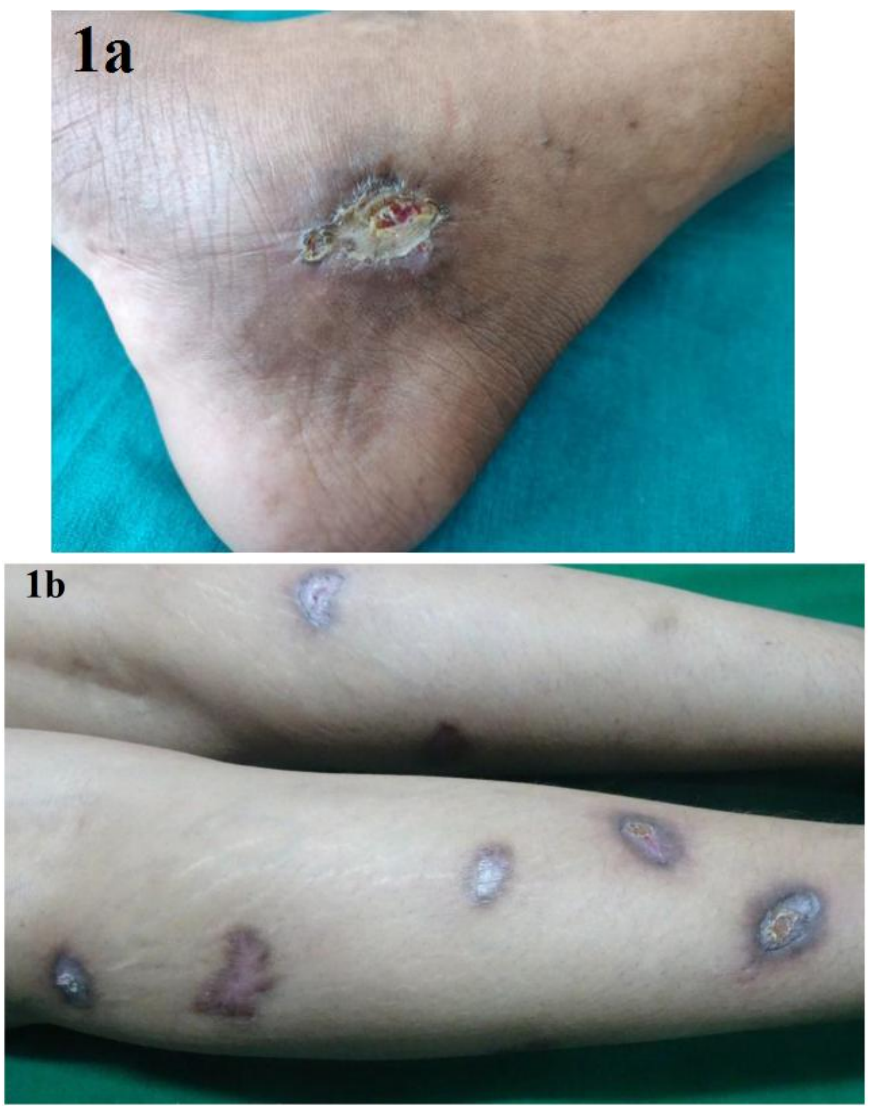

Fig 1a \& 1b. Multiple well defined, punched out ulcers of size around $2 \times 2 \mathrm{~cm}$ with perceptible violaceous hue of the margin. The surrounding skin was hyperpigmented and indurated.

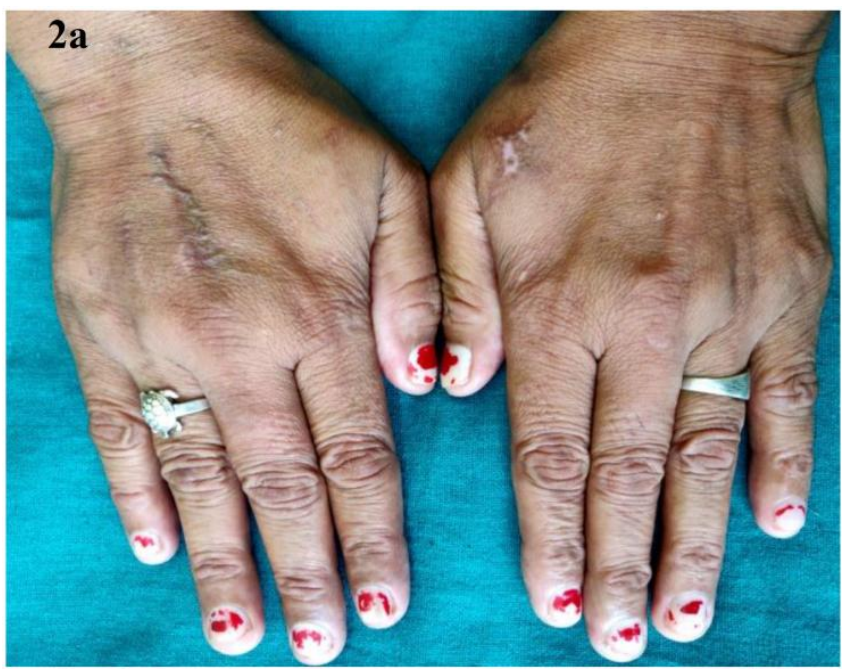

Fig 2a: Thrombosed veins over dorsa of right hand with atrophic scars over left hand

\section{$2 b$}

Fig 2b: Multiple Atrophic scars over left arm.

\section{Discussion}

Pentazocine was introduced in 1967 as a potent analgesic for parenteral use. By 1969, the abuse potential of pentazocine had been recognized. Establishing a case of drug abuse is difficult as in our case, particularly when the history of selfmedication is not forthcoming. The diagnosis requires high index of suspicion and exclusion of other commoner causes of leg ulcers. Varied range of presentation of pentazocine induced ulcers include- irregular-shaped deep ulcers with black eschars and surrounding induration, ${ }^{[1,2]}$ halo of hyperpigmentation around the ulcer, ${ }^{[2]}$ woody induration, ${ }^{[1,2]}$ needle pricks/thrombophlebitis, ${ }^{[3]}$ puffy hand syndrome,${ }^{[4]}$ fibrous myopathy ${ }^{[5]}$ and difficulty in venous access. ${ }^{[6]}$ Investigations to establish the presence of pentazocine in urine are very useful in making the diagnosis, but their limited availability is a disadvantage. Pentazocine can be detected in the urine by thin layer chromatography, which is a qualitative test. Quantitative tests such as gas chromatography and gas chromatography/mass spectrometry are available in the research setting. No specific medical therapy is available. Surgical excision may be required. Spontaneous healing can occur after conservative treatment. ${ }^{[6]}$

\section{Conclusion}

Diagnosis of pentazocine induced ulcers is not easy and requires a high index of suspicion and 
any ulcer, which does not fit clinically in any common cause of ulceration, should arouse suspicion of pentazocine use/ abuse.

\section{References}

1. Schlicher JE, Zuehlke RL, Lynch PJ. Local changes at site of pentazocine injection. Arch Dermatol 1971;104 :90-1.

2. Parks DL, Perry HO, Muller SA. Cutaneous complications of pentazocine injections.

Arch Dermatol 1971;104:231-5.

3. Girolami A, Cella G. Acute superficial phlebitis in a patient with hemophilia A: Probably an iatrogenic effect. Acta Haemat 1972;48:307-11.

4. Neviaser RJ, Butterfield W, Wieche DR. The puffy hand of drug addiction: A study of pathogenesis. J Bone Joint Surg Am 1972;54:629-33.

5. Oh SJ, Rollins JL, Lewis I. Pentazocine induced fibrous myopathy. J Am Med Assoc 1975;231:271-3.

6. Prasad HR, Khaitan BK, Ramam M, Sharma VK, Pandhi RK, Agarwal S, . Diagnostic clinical features of pentazocine-induced ulcers. Int J Dermatol 2005;44:910-5. 